Journal of Advanced Computer Science \& Technology, 8(2) (2019) 16-22
Journal of Advanced Computer Science \& Technology
SPC
Website: www.sciencepubco.com/index.php/JACST
Research paper

\title{
Breaking through unravel problems in ERP implementation using agile
}

\author{
Santo Fernandi Wijaya ${ }^{1 *}$, Angelina Ervina Jeanette Egeten ${ }^{1}$ \\ ${ }^{1}$ Information Systems Department, School of Information Systems, Bina Nusantara University, Jakarta, Indonesia \\ *Corresponding author E-mail: santofw@binus.ac.id
}

\begin{abstract}
Demand for the industry to enhance competitive advantage. For that, the industry is required to make a breaking through in order to enhance the organizational performance. This is a reason for addressing the inefficiencies in managing people, processes, organizations, and technology. One of the efforts in improving organization performance is the development in the field of Information Systems as an effort to improve the agility of the organization. ERP system is one solution that can be employed in order to improve organization performance. However, in reality, industrial companies face problems in ERP implementation. This is a challenge to solve the problems of implementing an ERP system for industry. In this opportunity, researchers intend to conduct a re-search to identify the problems of factors in the ERP implementation, namely by proposing agile methods as one of the new methodologies in the effort to solve the problems in the ERP implementation for an industry. The results of this study will result in an agile model of implementing ERP for improving the capacity of ERP systems. This study idea is to analyze the agile method as a solution alternative to make changes for the ERP implementation success. This study is using Structural Equation Modeling as a quantitative data analysis approach of an industry as a case study.
\end{abstract}

Keywords: Agile Method; Implementation; ERP System.

\section{Introduction}

Changes in business patterns in the digital age of this information require the company to able to make decisions quickly and precisely, especially for the manufacturing industry. This causes the company to employ an integrated information system as a support tool for strategic decision making. Information systems and information technology have a very important role to support the smooth operation of activities in order to improve the working methods more effectively, efficiently and productively. Enterprise Resource Planning (ERP) system is an optional solution as an effort in achieving it. ERP system is an integrated information system that synergizes for managerial functions within a company, such as: Accounting and Finance, Manufacturing, Sales and Marketing, Purchasing, Logistics and Inventory, Human Resource. The purpose of the ERP system is to influence the changes in business processes following the workings of ERP, so that it can only provide various strategic business information that is appropriate and fast, and help managerial level in making decisions appropriately and quickly, and affect the performance of the company and provide optimal benefits for the company. To achieve this, it is determined how the ERP system can be successful in the implementation phase. Stages of ERP system implementation can be considered important and require concentration and commitment level of management for the success of ERP implementation. The ERP project can be said to be a management project, where the management level not only approves in the ERP vendor selection, approves the relative great value for ERP investment, approves the ERP project team, but more than that, the management level is required to be actively involved in the overall implementation stages, stages of planning (pre-implementation), implementation stages of implementation, and stages after implementation (post-implementation). Based on previous research literature studies, most ERP project failures are caused by a lack of management level focusing on the overall stages of the implementation. Stages of ERP implementation are crucial factors that must be taken seriously by considering and identifying the success factors in implementing the ERP system. In reality, researchers found a variety of complexities in determining the method of ERP system implementation. This is what triggers a failure in the ERP implementation. To solve the problems, the researcher intends to do research on the methodology in the implementation stage of ERP system; that is how to develop new methodology modeling as one of alternative for ERP system implementation with a case study on companies in AMG. The results of this study are expected to produce an agile method as a solution to solve problems in the ERP implementation that can be used an industry, so as to improve organizational performance.

Based on the above background, the researchers formulate the research questions in this study as follows:

1. What are the factors of problems in the ERP implementation for an industry?

2. Can agile methods be used as alternative approaches to address problems in implementing ERP systems for an industry?

The result of this research is to produce agile modeling as a solution to solve problems in ERP system implementation. The purposes of this study are as follows:

1. Identify factors of problems in the implementation of an industrial ERP system.

2. Analyze agile methods as alternative approaches that can a breaking through unravel the problems in implementing ERP systems for an industry 


\section{Theoretical background}

\subsection{Implementation of ERP systems}

ERP system implementation requires active business process change and feedback [15]. Success in the ERP system implementation process will have an impact for the company, such as: decision making process becomes faster and more precise, changes in the style of corporate organizational structure that becomes more dynamic, lean, flexible and more synchronized . Implementation of an ERP system becomes an important fundamental thing for a company in order to improve company performance. Therefore, in order to implement ERP system effectively and can support various functions within a company, it must be designed using a methodology that is expected to eliminate repetitions of work process, improve product quality and service to customer. It can be said that ERP system implementation process will improve the business process running by following the business process of ERP system, with proven the simplification of business process, improvement of customer service quality, timeliness in production and distribution process. Thus, it can improve managerial functions in decision making to be more precise, focused and fast.

\subsection{Challenge of ERP system}

It's explained that the purpose of the ERP system was to integrate various information as needed for the managerial level in making decisions become more trivial, fast, and accurate [15]. This becomes the challenges of the ERP system, which are the integration of data and information from the ERP system. The function of ERP system integration ensures that ERP applications run well, such as: no repetition of work, decision making process becomes relatively faster. This will prove a change in the way efficiency and effectiveness work. ERP system challenges cover the following [7]:

- Technology selection

Is a consideration of management leaders in making investments? Management support in technology selection will affect the performance of ERP systems.

- Change management

Changing the running business process that follows the selected ERP system, needs technological supports. The factors of people, processes and technology are the three fundamental things of management decisions to make the process of management transformation. This management transformation process is to conduct the changing of working procedures that follow the workings of the selected ERP system.

- Knowledge Management

Knowledge Management Modeling becomes ERP system challenge to achieve success in implementing ERP system. As it is known that the purpose of ERP system is to improve the way the work becomes more effective, efficient, and productive. For that, it takes information processing from knowledge management initiatives. Knowledge management by managing knowledge becomes organized as a means of sharing knowledge and gaining increased flexibility. Improved knowledge management will increase flexibility and innovation and in the context of ERP systems, knowledge management is a critical success factors [27].

- Emerging Technologies

Technology becomes an important role in improving the process, flexibility, and speeds up the decision-making process precisely, accurately, and up to date.

\subsection{ERP Complexity}

Complexity is an effort related to achievement of performance in accordance with predetermined objectives and reduce effects in the completion of complex tasks. Complexity is a problem-solving solution that comes from diverse and conflicting with performance, behavior, fault tolerance, security and dependency, Complexity is determined largely by the selection of business processes supported by the system or module to be implemented [14, 16,30]. Complexity is used not only in special cases but also in the standard methodology used to manage information systems or systems management projects. Complexity is further enhanced by cultures, different business processes, complex financial arrangements and possible political interventions by interested parties. Complexity is a significant problem for the managerial level and can impair operational performance if not managed properly or if managed properly can be used to gain strategic advantage [14]. ERP system is a complex software that becomes the reason to experience ERP implementation failure, that is because experiencing complexity in ERP implementation and have to do business process change [3]. The complexity of ERP is due to changes in business processes. This ERP complexity can be used for management to commit to the proper procurement of resources in implementing ERP system implementation projects. Implementation of ERP is based on an understanding of the current business processes used by the company as a whole and should provide a basis for alignment for future business processes [4]. ERP complexity is categorized into two dimensions: functional vs non-functional, and back-end vs. front-end. The back-end complexity to provide the required functional core that meets the non-functional aspects. The complexity of users in translating business processes in enterprise applications is the need to make adjustments to the business processes running in data input. It's suggested that ERP implementation is a complex system for achieving noncentralized organization with different business processes and business systems [9,28]. The complexity of an ERP system is determined by changes in the business processes of the selected system. The type of project management complexity is the complexity of the organization and the complexity of the technology. The complexity of the organization refers to the number, and relationship, hierarchical level, organizational unit, and specialization. The complexity of technology refers to quantities, and relationships, inputs, outputs, tasks, and technologies $[16,32]$. In addition, the complexity of developing the Information system is a manifestation of the high failure rate historically from the information system development project. ERP implementation projects are complex and often exceed the budget and time specified [28]. The complexity of the ERP implementation project is also due to the demand for customization of the ERP system. It's illustrated that the complexity of an ERP system is an ERP implementation, which requires managers to have extensive knowledge to support ERP implementation projects. Based on the exposure, it can be said that ERP implementation process is the complexity of ERP system, which translates the business process of ERP system to do with business process running, so no customization request required for business process adjustment goes with ERP business process system. This is the complexity of the ERP system, which is the process of changing business processes.

\subsection{ERP project management}

The agile development approach differs from traditional approaches, ie approaches that emphasize more business processes simpler and adapt dynamically [12]. Factor project management component for the development of system information is the coverage management, human resource management, risk management, procurement management, and integration management [28]. In many cases, packaged ERP products do not provide all the solutions to an industry's business processes, causing a gap to customize the existing ERP products 
[2]. For this, it is necessary to approach project management methods in managing ERP implementation projects with adaptive adjustments to suit business needs. This method is known as agile project management for ERP as project management used in ERP implementation to provide adaptability to the application of agile methods to support business process change and technology trend support. The development of ERP systems supports business process changes from tactical operations to a strategic level [21]. Such development enables ERP implementation to be more complicated, requiring the use of new technologies and methods to support more agile behavior of ERP systems. The development of agile ERP system uses the separation of business logic in business rules and components of traditionally developed ERP systems. Information technology projects are vulnerable to changes in the business environment, and increased speed of change in business such as ERP implementation planning [7]. Successful implementation of ERP depends on solving problems in the project management process. such as: poor project management, inadequate allocation of human resources, and vendor management. This problem poses a challenge to the success of ERP projects by reengineering in implementing ERP implementation, identifying the key elements of project management that contribute to the successful implementation of ERP. One of the main challenges in implementing an ERP system is how to manage project management efficiently. Building project management in the implementation of an ERP system is important by applying business process management concepts to support project management activities as a strategy to overcome the complexities of ERP implementation and achieve agile organization in decision making and performance improvement. The main stages of project management ERP system implementation include the stage definition, planning, executive and delivery. In all of these stages, active managerial level involvement will determine the implementation process to run on a predetermined target. ERP implementation is not just an IT department project but all levels of managerial departments within the organization must be actively involved in managing business process changes following the business process of the ERP system. It's stated that interaction and iteration are the foundations for successful project management, especially focusing on strong business; agile practices facilitate interaction and iteration; adding business understanding to help develop project management [21]. The successful implementation of ERP requires good project management, where companies must have effective business strategies and tactics [10]. The main phase of the project life cycle depends on the active involvement of all stakeholders. The main stages of project management include the stages of definition, planning, executive and delivery. Managing business process changes to coordinate action in completing each task to achieve business goals. Many organizations experience ERP implementation failures due to lack of focus on changes in business processes and management changes. Change management is one of the important factors to achieve the success of ERP implementation. Business process reengineering has a close relationship with ERP implementation, where re-engineering changes must be done iteratively and in accordance with business strategic alignment. ERP system project management becomes a significant challenge to success in ERP implementation. To that end, the ERP system must meet the business needs with the involvement of related parties, so it becomes very important to select the best people who are members of the project implementation team, ERP vendors, and consultants. The ERP implementation project team is responsible for communicating across departments, developing detailed project plans, determining project schedules, so that the project schedule development process is a critical factor, as it affects the time duration, project budget, and project completion targets in a timely manner. The cycle ERP system project management can show in figure 1 .

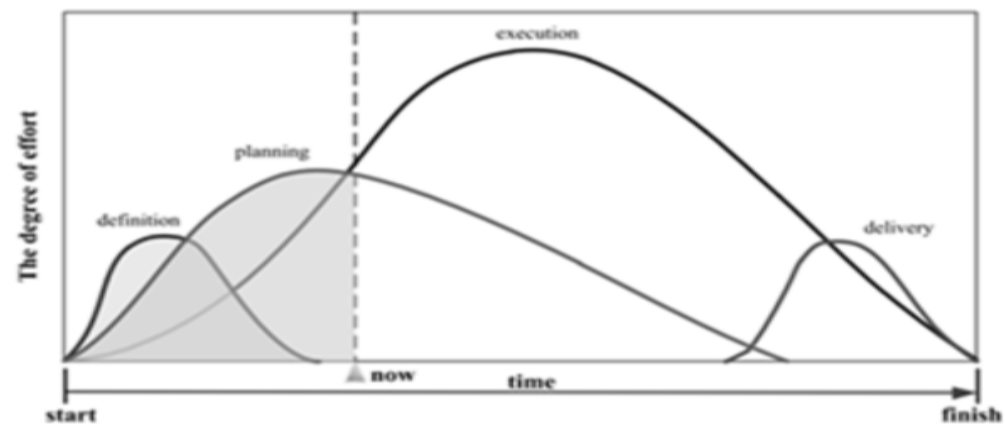

Figure 1: ERP Project Management Cycle [10].

\subsection{Agile approach}

Agile is an approach to system design and development based on incremental and iterative processes. The Agile approach is flexible and iterative with continuous feedback and constant communication [6]. Agile of ERP systems is IT Integrator (system integration, ICT infrastructure, and IT service and outsourcing) [24]. Agile approach can reduce the risk of ERP implementation failure. The agile method approach is an information system development that focuses on flexible and interactive, and communication. Agile method approach can describe how to work with flexibility, interact and cooperate with customer to ensure problem solving to business process. Agile methods as a method of evolution in business and management in general, and in the development of management projects in particular [18]. The agile method has a flexibility and work style that focuses on customer needs, and ensures work satisfies business needs. The traditional approach, although aimed at quality, but the fixed focus is the feature, and the variable is time and cost. While the agile approach, aiming at quality, but the fixed focus is time and cost, and variable factors are features. Thus in the agile approach prioritizes terms of delivery time and cost versus features. A comparison of traditional approach vs agile approach can be seen in the following in figure 2.

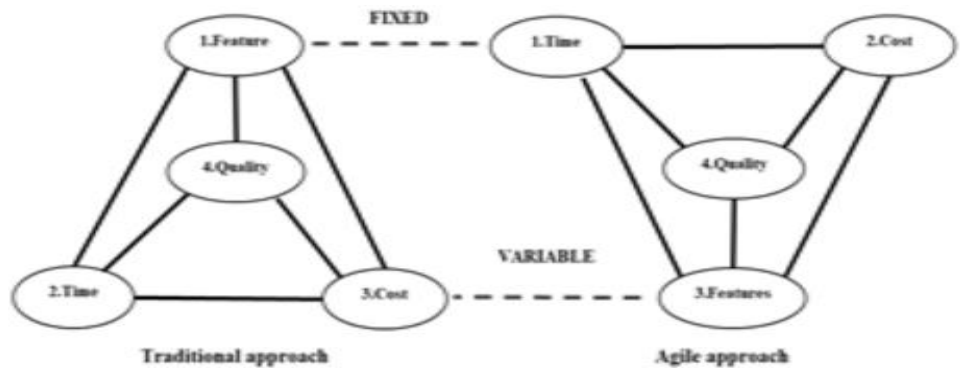

Figure. 2: Comparison of Traditional vs Agile Approach [18]. 
Based on the exposure, it becomes a challenge for researchers to conduct further research in an effort to overcome the problems of ERP system implementation for industry, especially textile industry in Indonesia. Research on agile methodology as a solution to overcome the complexity of ERP implementation for the industry can be considered relatively minimal because it has only been done for the last 3 years and only done for certain industries.

\subsection{Agile method}

The framework provides a way of thinking about the implementation of choices to make engineering managers understand and evaluate these choices. Technology, Organization, Environment is a classic framework that proposes the likelihood of innovation / technology adoption $[1,13]$. The framework proposes three bits of enterprise contexts that influence the adoption and / or implementation of innovations Developing agile modeling is one of the alternative approaches to consider in solving the complexity of implementing ERP systems for industrial companies. The agile methodology identifies the critical success factors (Critical Success Factors) in developing information systems. The principles of agile methods are processes, people, and products, practices, focused on business needs, timely delivery, information collaboration, product quality, continuous and clear communication, and strict monitoring [18]. The agile principle is the constant delivery of time, the intensive interaction of people, the motivated person, and good face-to-face communication, the role of the software that works optimally, the constant speed, the technical excellence and the good design, simplicity, a compact work team, a continuous improvement process [5].

\section{Research method}

\subsection{Research design}

The methodology used in this research is through case study approach, analysis, evaluation, and literature study. To answer the related problems factors in the implementation of ERP system, the researchers perform the analysis result based on Systematic Literature Review (SLR) method. In addition, the preparation of this methodology uses the Structural Equation Modeling (SEM) technique to manage the data available in the company as the case study of this study as the basis for answering the formulation of the problem in this study. Based on the results of the methodology analysis, the researchers will process in the prototype design according to the object of research related agile methodology for ERP system.

\subsection{Data collection techniques}

To obtain data and information in the processing of data and information objectively, the researchers perform data collection techniques, which are as follows:

a) Literature review

Researchers conducted literature studies as a distinguished reference to this research topic, such as: books, E -books, scientific journals, scientific conferences and other references.

b) Interview

Researchers collect data by conducting interviews. Interview as a research instrument, where the researcher prepares a list of questions in accordance with the subject matter of this study. Researchers conducted interviews with managerial levels and people related to this research topic.

c) Observation

Researchers make direct observations on the business unit as a case study of this study. In this study, researchers analyzed the ongoing business processes, studied information required managerial levels, and the technology and information systems infrastructure used, and evaluated the performance of ERP systems used in related companies.

d) Questionnaire

The questionnaire is a data collection technique that is conducted by giving a written set of questions that will be distributed to the relevant parties in the case study in this study.

\subsection{Research methodology}

To clarify the stages of this study, the researchers describe the research methodology for analyze key factors that determine methodology of ERP implementation as follows: systems, people, management, technology, and process. Detail of research methodology can show in the figure 3 .

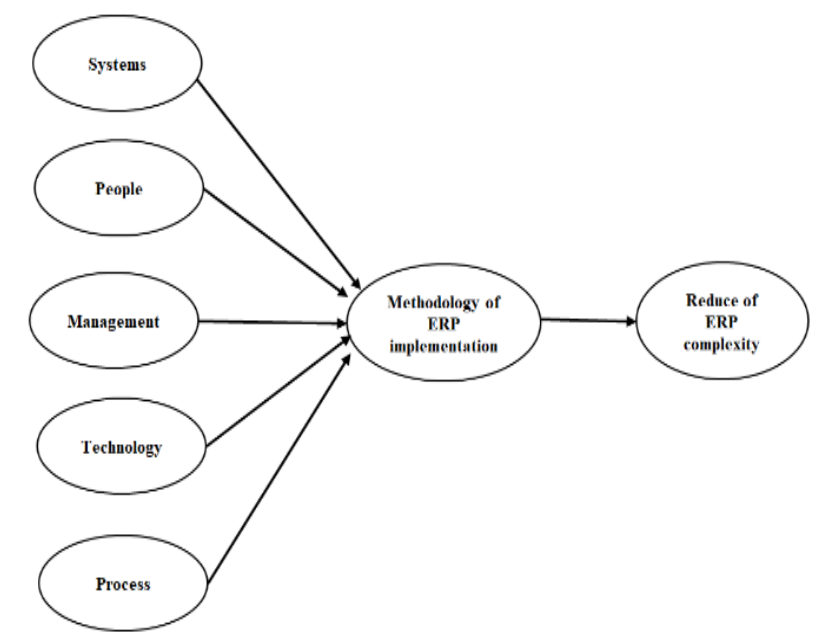

Figure 3: Research Methodology. 


\subsection{Research design}

In conducting the test and validation process on the feasibility of this research model and design, the researchers use quantitative methodological research methodology called "Structural Equation Modeling (SEM)" to answer the formulation of this dissertation problem. Structural Equation Modeling (SEM) technique is a statistical technique capable of evaluating complex hierarchical dependencies and related context variables that have been proven to be effective in applying context sensitive data [23]. To evaluate the reliability and validity of the outer model measurements of the SEM model, it will be tested through: [23]

- Indicator Reliability: a reflective indicator that gives an indication of the measurement of the variance level described by the related construction.

- Construct Reliability: Reliability indicator to show inadequate reflective indicator measurement of the related construction.

- Convergent Validity: The measurement of convergent validity considers the correlation between responses obtained by different methods to measure the same construction.

- Discriminant Validity: Consider the degree of inequality in measurements obtained by measuring devices for different constructions.

In order to obtain the results of research in general, then make a list of questionnaire questions, namely as follows:

The data of respondents:

$\begin{array}{ll}\text { - Gender } & : \text { Male / Female } \\ \text { - Position } & : \\ \text { - Age } & : \\ \text { - The education level of alumni } & :\end{array}$

This study aims to analyze and implement it in Enterprise Resource Planning (ERP) in the textile industry.

Level of approval:
1. Strongly disagree
5. Somewhat agree
2. Disagree
6. Agree
3. Somewhat disagree
7. Strongly agree

4. Neutral

Table 1: List questionnaire and categories

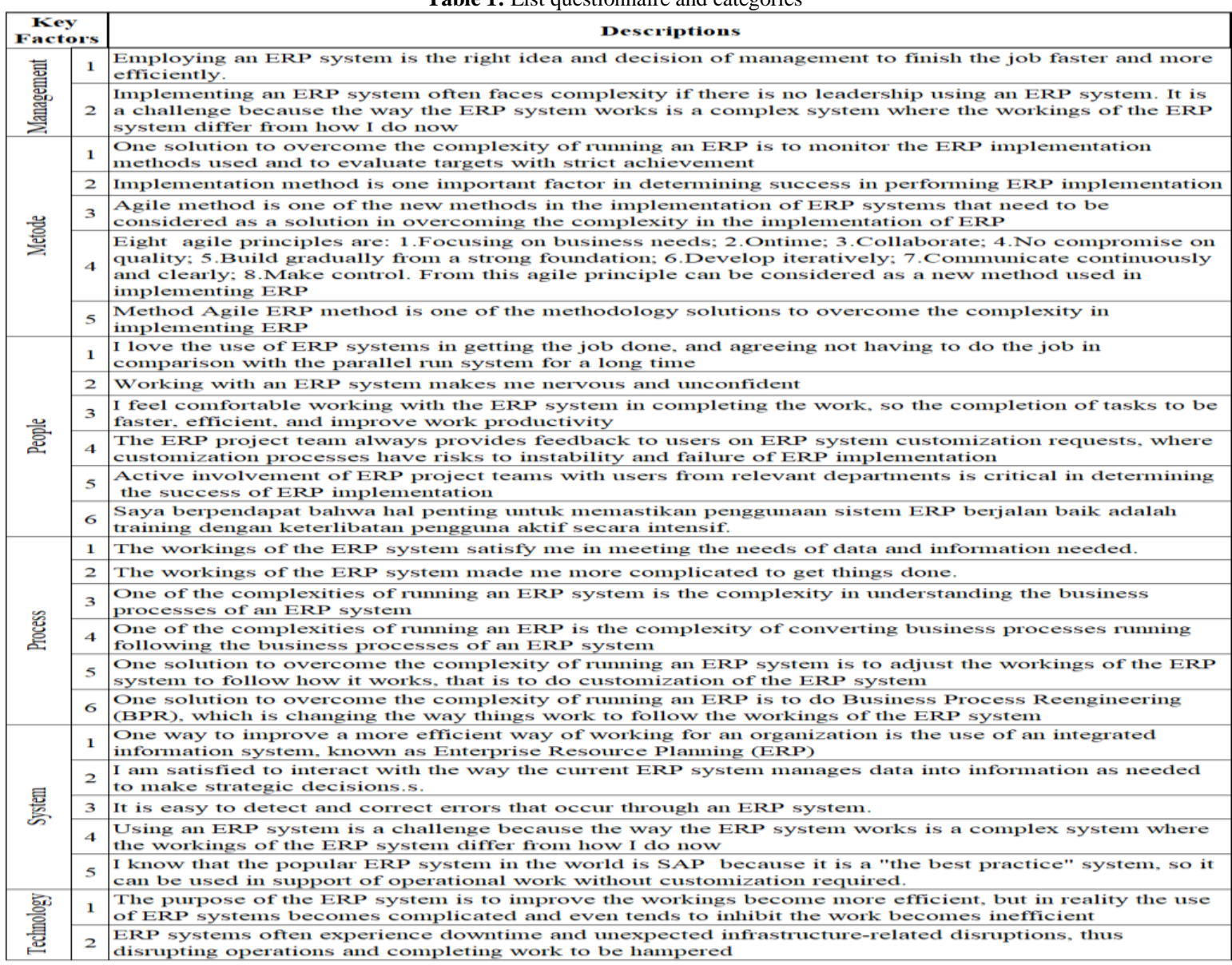




\section{Results}

\subsection{Factors of problems in the implementation of ERP systems for an industry}

Based on online searching source database of published papers related to agile method and problems of ERP implementation, the researchers map the similarity of models based on the components that become the main issue against agile method and problems of ERP implementation. Based on the results of comparative literature studies conducted by researchers on factors that become factors problems in the implementation of ERP systems against agile methods as project management, can be seen in the following table

Based on the results of the questionnaires, the researchers conducted data management using Partial Least Squares Structural Equation Modelling (PLS-SEM) method, with the following results in figure 4.

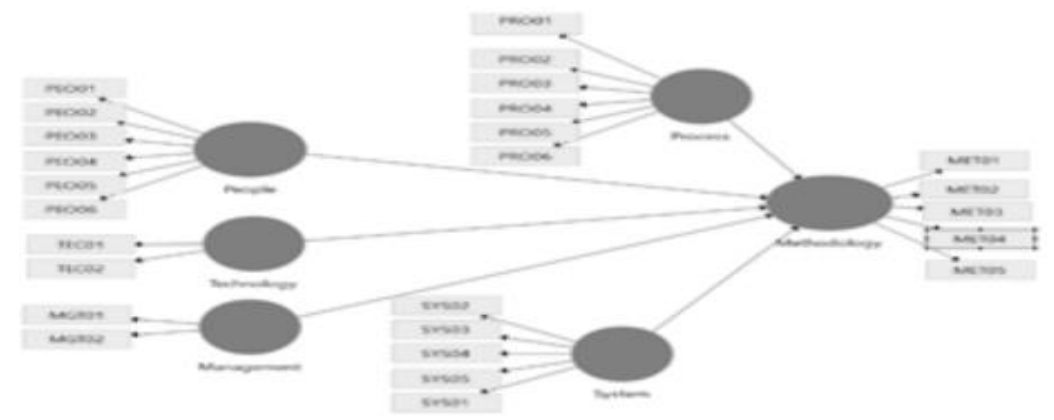

Figure 4: Squares Structural Equation Modelling.

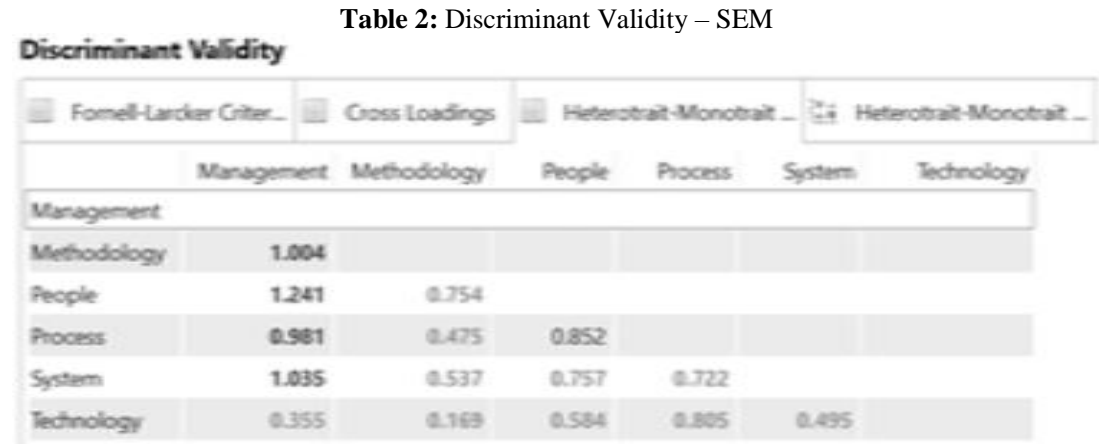

Based on the results of calculate of Discriminant Validity using the PLS-SEM method, it can be said that people, methodology, and system becomes critical factors for supporting the ERP implementation.

Table 3: Collinearity Statistics - SEM

\section{Collinearity Statistics (VIF)}

\begin{tabular}{|c|c|c|c|c|c|c|}
\hline \multirow{2}{*}{ Inner VIF Value } & \multicolumn{2}{|c|}{ Outer VIF Values } & \multirow[b]{2}{*}{ People } & \multirow[b]{2}{*}{ Process } & \multirow[b]{2}{*}{ System } & \multirow[b]{2}{*}{ Technolo } \\
\hline & Management & Methodology & & & & \\
\hline Management & & 1.781 & & & & \\
\hline \multicolumn{7}{|l|}{ Methodology } \\
\hline People & & 1.817 & & & & \\
\hline Process & & 1.664 & & & & \\
\hline System & & 1.519 & & & & \\
\hline Technology & & 1.084 & & & & \\
\hline
\end{tabular}

Based on the results of calculate of collinearity statistics using the PLS-SEM method, it can be said that the determination of the implementation methodology becomes very significant in overcoming the difficulties of implementing the ERP system, where the factors of people, management and process become the dominant factors. Thus the ERP project should involve managerial and user level people to make business process changes following the business processes of the ERP system. Based on comparative literature study results, it can be concluded that the main component of the concept of agile method can be used as an alternative approach in overcoming the problems of ERP system implementation. Components of the agile method are people ability, management support, business value, project management, quality, and process change business.

\subsection{Agile method can be used as an alternative approach a breaking through unravel problems in implementing ERP systems for an industry}

Based on the results of observation, mapping the results of the questionnaire conducted by researchers to the correspondents who are users who experienced and actively involved in the implementation stages in companies in AMG, and also to the academic correspondents who understand and related ERP system. Here are the results of processing through SEM techniques related to problems factor in the implementation of ERP systems for the industry, can be seen. Changing the business process to run following the business process of the ERP system is important, so it does not require business process customization process of the ERP system. This has an impact on a breaking through unravel problems in implementing the ERP system. 


\section{Conclusion}

One significant factor to achieve successful implementation of ERP system is the implementation methodology. Most ERP system implementation methodologies still employ traditional methods. For that, consider another method in the implementation of ERP system, that is agile method. Agile method is an approach in the development of a popular system and focuses on major software development, enabling companies to migrate into agile approaches. The agile method will improve the way work is more efficient, the response speed and relatively simpler in managing business processes. Agile method is a modern method for industry in managing business process more effectively and efficiently, speeding up production time, improving speed, product quality, and be responsive to fulfill customer requirement. The characteristics of agile methods can anticipate uncertainties and allow relatively rapid changes to achieve "responsive". Based on the results of data management analysis in this study, it can be extrapolated that agile method is an implementation methodology that needs to be considered for industry, especially textile industry in implementing ERP system, where agile method have suitable characteristic in implementing ERP system and can develop agile ERP model to address a breaking through unravel problems of ERP implementation for the industry. In addition, agile ERP methods can connect most departments, support information flows within the organization, and also connect with external parties. Nevertheless, the role of people who have the insights and thinking of technology to develop the company's business processes through the support of modern technology is essential to ensure the success in implementing ERP systems for the textile industry. Researchers realize that this research is still not perfect as it has limitations in managing data, research methods, and coverage of the textile industry only. Therefore, this research will be continued in subsequent research with qualitative research method, with coverage of industries, to contribute and a breaking through unravel problems to the constraints faced industries in implementing ERP system.

\section{References}

[1] Awa, H. O., Ukoha, O., \& Emecheta, B. C. (2016). Using TOE theoretical framework to study the adoption of ERP solution. Cogent Business \& Management, 3(1), 1196571. https://doi.org/10.1080/23311975.2016.1196571.

[2] Alleman, GB (2002). Agile project management methods for ERP: how to apply agile processes to complex COTS projects and live to tell about it. In Conference on Extreme Programming and Agile Methods. Springer, Berlin, Heidelberg. https://doi.org/10.1007/3-540-45672-4 8.

[3] Bansal, V \& Negi, T. (2008). A metric for ERP complexity. In International Conference on Business Information Systems (pp. 369-379). Springer, Berlin, Heidelberg. https://doi.org/10.1007/978-3-540-79396-0_32.

[4] Bernroider, EW. (2008). IT governance for enterprise resource planning supported by the DeLone-McLean model of information systems success. Information \& Management, 45(5), 257-269. https://doi.org/10.1016/j.im.2007.11.004

[5] Campanelli AS \& Parreiras FS. (2015). Agile methods tailoring-A systematic literature review. Journal of Systems and Software, 110, 85-100. https://doi.org/10.1016/j.jss.2015.08.035.

[6] Chang, M. (2010). An Agile approach to library IT innovations. Library Hi Tech, 28(4), 672. https://doi.org/10.1108/07378831011096303.

[7] Chen, CC., Law, CC., \& Yang, SC. (2009). Managing ERP implementation failure: a project management perspective. IEEE transactions on engineering management, 56(1), 157-170. https://doi.org/10.1109/TEM.2008.2009802.

[8] Kaushik, S., Bharadwaj, A., Awasthi, V., \& Sharma, R. (2017). GenNext: Framework for Optimizing ERP Implementations. Indian Journal of Science and Technology, 10(24). https://doi.org/10.17485/ijst/2017/v10i24/110913.

[9] Krishnadan, RS. (2017). A Studi of ERP implementation in select industries (Doctoral dissertation, Gujarat Technological University Ahmedabad).

[10] Luo, W., \& Strong, D. M. (2004). A framework for evaluating ERP implementation choices. IEEE transactions on Engineering Management, 51(3), 322-333. https://doi.org/10.1109/TEM.2004.830862.

[11] Laurie D Hughes, Nripendra P. Rana, Antonis C. Simintiras. (2017). the changing landscape of IS project failure: an examination of the key factors, Journal of Enterprise Information Management, Vol. 30 Iss: 1. https://doi.org/10.1108/JEIM-01-2016-0029.

[12] Lee, G., \& Xia, W. (2010). Toward agile: an integrated analysis of quantitative and qualitative field data on software development agility. Mis Quarterly, 34(1), 87-114. https://doi.org/10.2307/20721416.

[13] Luo, W., \& Strong, DM. (2004). A framework for evaluating ERP implementation choices. IEEE transactions on Engineering Management, 51(3), 322-333. https://doi.org/10.1109/TEM.2004.830862.

[14] Mason, P., \& Cosh, K. (2008). Managing complexity in ICT systems development. International Journal of Information Technology and Management, 7(3), 264-282. https://doi.org/10.1504/IJITM.2008.017605.

[15] Michael sherman, stephen edison, benjamin rehberg, martin danoesastro (2017) Taking agile way beyond software, BCG.

[16] Holub, I \& Bruckner, T. (2016). Measuring complexity of SAP systems. Complex Systems Informatics and Modeling Quarterly, (8), 60-67. https://doi.org/10.7250/csimq.2016-8.05.

[17] Ranjan S Jha, VK \& Pal P. (2016). Literature review on ERP implementation challenges. International Journal of Business Information Systems, 21(3), 388-402. https://doi.org/10.1504/IJBIS.2016.074766.

[18] Quint wellingtong redwood (2017)

[19] Sousa, N., Costa, C. J., \& Aparicio, M. (2013). IO-SECI: A conceptual model for knowledge management. In Proceedings of the Workshop on Open Source \& Design of Communication (pp. 9-17). ACM https://doi.org/10.1145/2503848.2503850.

[20] Staphorst, L., Pretorius, L., \& Pretorius, T. (2013). Structural equation modelling based data fusion for technology forecasting: A generic framework. In Technology Management in the IT-Driven Services (PICMET), 2013 Proceedings of PICMET'13: (pp. 2163-2170). IEEE.

[21] Schmidt, C., \& Sun, W. N. (2018). Synthesizing Agile and Knowledge Discovery: Case Study Results. Journal of Computer Information Systems, 58(2), 142-150. https://doi.org/10.1080/08874417.2016.1218308.

[22] Smaizys, A., \& Vasilecas, O. (2009). Business Rules based agile ERP systems development. Informatica, 20(3), 439-460.

[23] Staphorst, L., Pretorius, L., \& Pretorius, T. (2013). Structural equation modelling based data fusion for technology forecasting: A generic framework. In Technology Management in the IT-Driven Services (PICMET), 2013 Proceedings of PICMET'13: (pp. 2163-2170). IEEE.

[24] Tr'bka, J., \& Soja, P. (2014). Agile versus design-based approach to ERP system implementation: A cross-case study.

[25] Tareq Q. (2016). Avoiding the Most Common ERP Challenges with Agile Methodologies.

[26] Tripp, J., \& Armstrong, DJ. (2018). agile methodologies: organizational adoption motives, tailoring, and performance. Journal of Computer Information Systems, 58(2), 170-179. https://doi.org/10.1080/08874417.2016.1220240.

[27] Usman UMZ \& Ahmad MN. (2012). Knowledge Management in success of ERP systems. International Journal of Advances in Engineering \& Technology, 21, 21-28

[28] Uflacker, M., \& Busse, D. (2007). Complexity in enterprise applications vs. simplicity in user experience. Human-Computer Interaction. HCI Applications and Services, 778-787. https://doi.org/10.1007/978-3-540-73111-5_87.

[29] Uppstrom, E., Lonn, CM., Hoffsten, M., \& Thorstrom, J. (2015). New implications for customization of ERP systems. In System Sciences (HICSS), 2015 48th Hawaii International Conference on (pp. 4220-4229). IEEE. https://doi.org/10.1109/HICSS.2015.505.

[30] Valdeza, A. C., Braunera, P., Schaara, A. K., Holzingerb, A., \& Zieflea, M. (2015). Reducing complexity with simplicity-usability methods for industry 4.0. In Proceedings 19th triennial congress of the IEA (Vol. 9, p. 14).

[31] Xu L, Wang C, Luo X, Shi (2006). Integrating Knowledge Management \& ERP in enterprise systems. International conference, researchgate: Systems Research \& Behavioral Science 23(2), 147-156. https://doi.org/10.1002/sres.750.

[32] Xia, W \& Lee, G. (2005). Complexity of information systems development projects: conceptualization and measurement development. Journal of management information systems, 22(1), 45-83. https://doi.org/10.1080/07421222.2003.11045831. 